\title{
Article
}

\section{Supporting the Integration of Sustainability into Higher Education Curricula-A Case Study from Switzerland}

\section{Sandra Wilhelm Hamiti ${ }^{1, *}$ and Hans Wydler ${ }^{2}$}

1 éducation21, Swiss Foundation for Education for Sustainable Development (ESD), Department of ESD development, Monbijoustr. 31, Postfach, 3001 Bern, Switzerland

2 Institute of Natural Resource Sciences, Centre for Urban Greening (Green Care), Department of Life Sciences and Facility Management, Zurich University of Applied Sciences, Campus Grüental, Postfach, 8820 Wädenswil, Switzerland; E-Mail: hans.wydler@zhaw.ch

* Author to whom correspondence should be addressed; E-Mail: sandra.wilhelm@education21.ch; Tel.: +41-31-321-00-17.

Received: 1 April 2014; in revised form: 8 May 2014 / Accepted: 12 May 2014 /

Published: 27 May 2014

\begin{abstract}
From the perspective of different stakeholders, education for sustainable development (ESD) in higher education is highly desirable. In practice, however, this may present challenges, as it involves systemic and cultural changes as well as organizational transformation. A working group at the Zurich University of Applied Sciences supported such a transformative process with the aim of fostering, linking and subsequently deepening the dimensions of sustainable development in the existing curricula. By means of an assessment tool (spider diagram) developed through a bottom-up action research procedure, the working group initiated a discussion on sustainability among university lecturers, research associates and students. Results support the hypothesis that resistance to incorporating dimensions of sustainability into the curriculum can effectively be avoided by such an approach. The effectiveness of the assessment tool increased the commitment and the willingness of lecturers to share a common goal of demonstrating the relevance of sustainability in higher education.
\end{abstract}

Keywords: sustainable development in higher education; assessment of sustainable development; curricula; teacher training; bottom-up processes; qualitative research; case study 


\section{Introduction}

This article describes the institutionally based way in which the Institute of Natural Resource Sciences (IUNR) at the Zurich University of Applied Sciences (ZHAW) seeks to respond to the challenge of sustainability in higher education. In this example, a tool or instrument is presented that has been designed to help shift the curriculum at Bachelor's level towards sustainability in a systematic way. The paper demonstrates how this assessment tool was created and used to support the integration of sustainability into the curriculum.

The sustainability agenda is becoming increasingly relevant to higher education $[1,2]$. The following current general political conditions for sustainability in higher education in Switzerland show why the transition of curricula to include a focus on sustainability is necessary:

- The Sustainable Development Strategy 2012-2015 of the Swiss Federal Council contains a series of measures to achieve sustainable development. These measures are structured according to ten key challenges, including the consistent application of sustainable development principles to education, research and innovation.

- Both the «UN World Decade of Education for Sustainable Development» and the corresponding action plan 2007-2014 of the Swiss Conference of Cantonal Ministers of Education have the integration of sustainable development principles in all areas of education as their main focus.

- All Swiss universities of applied sciences are federally accredited. In addition to reviewing their managerial and organizational structures, sustainability is also assessed as a review topic.

These general political conditions pose a major challenge to the Swiss education system. Nevertheless, in 2009 the Institute of Natural Resource Sciences decided to respond to this challenge in its study programme. There is, however, considerable internal resistance on the level of personal attitudes of stakeholders such as lecturers, although this is contrary to the political and organizational mandate of the ZHAW. For this reason, motivating lecturers to focus on sustainable development was included as part of the redesign of the curriculum of the existing Bachelor of Science (BSc) in Natural Resource Sciences programme. This focus is to be incorporated into all study programmes and courses.

\section{The Concept of Sustainable Development}

The Bachelor's programme in Natural Resource Sciences at the Zurich University of Applied Sciences prepares students for new professional fields that are being created as a result of the challenges of sustainable development. The curriculum focuses on responsible and sustainable use of natural resources, as well as on respect and responsibility for man and the environment. The study programme combines scientific subjects with engineering, and social and economic disciplines. In October 2009, a working group, consisting of six university lecturers with a system-oriented interdisciplinary background (i.e., social scientists, environmental scientists and natural scientists), were instructed by the management of the IUNR to foster and anchor sustainable development in the curriculum and to crosslink modules with regard to their sustainability content. The two authors of this article are also members of this working group. 
In this context the concept of sustainable development reflected by the curriculum should be considered. This concept refers to the "Our Common future" report published by the United Nations World Commission on Environment and Development (i.e., Brundtland Report, 1987) [3]. A number of models have been constructed for the identification of sustainability, based on this understanding. The best known in Europe and Switzerland is the three-pillar model, which considers economic, ecological and social dimensions. In this model, ecology may be given different weightings (e.g., strong and weak sustainability).

In many approaches to sustainability assessment a number of indicators are identified for each particular dimension. However, this approach is deficient in several respects as it neglects the fact that, while these indicators may be considered and evaluated in isolation, in the three-pillar model of sustainability they are understood to be interacting with each other systemically. As sustainability assessment usually takes place in a planned development process, Wiesmann and Messerli [4] conclude that sustainable development can only occur gradually, so that one definitive version of 'sustainability' does not exist and that this must always be negotiated anew as part of dynamic decision-making. Sustainable development can only be studied for a specific case (in a concrete social or organizational context). Generalisation from sustainability research is thus limited, and case studies and qualitative research approaches are moving into the foreground. Practical, interest- and implementation-related issues determine the research process.

Wiek and Binder [5] have developed three dimensions that are not only important for the design of decision-making processes in political circles, but also in companies. They refer to this as the "Construction of Sustainability Solution Spaces". In these spaces, three dimensions can be distinguished: a systemic, a normative and a procedural dimension (with the focus on the transformation of a system). These dimensions enable more technically-oriented sustainability assessment tools to be translated into socio-political decision-making processes. Again, it is the dynamic connections between these different dimensions that characterize the conceptual model. In Thierstein and Walser [6,7] these three levels appear in a similar manner: in addition to the systemic dimension of sustainability, the authors distinguish between the level of "politics and decision-making process" and the level of the "social value system" (i.e., ethics).

The working group decided to apply these perspectives to the teaching content in the Bachelor's study programme «Environmental Engineering». Teaching content can be understood as a number of systems that refer to objects in space and time, and can be studied in relation to the above-mentioned perspectives. Applied sciences are oriented to concrete social problems (the systemic perspective); they are application- and implementation-oriented (the procedural dimension), and every change, plan or project requires a consensus on the decisions involved. These in turn are based on values and beliefs (the ethical dimension). These perspectives produce a fresh way of viewing the issues that includes the key aspects of sustainability. Sustainability results from the dynamic analysis of the following three dimensions:

- Systemic dimension: This perspective is captured in the assessment tool with its ecological, economic and social dimensions as well as the dimensions of space and time, which together form the fundamental perspectives required for the empirical analysis of a system (see Figure 1). 
- Normative dimension: In this dimension, the connection to key concepts is created. In the assessment tool they are referred to as ethical principles. This level is intended to provide direction and the desired degree of implementation for system developments.

- Dimension of transformation or procedural dimension: this perspective examines the methods and approaches that contribute to the control and development of systems.

\section{The BSc-IUNR Example: From Theory into Practice (Case Study)}

Committing to sustainable development and integrating sustainability into the Bachelor's programme, while at the same time continuously developing an interdisciplinary curriculum and encouraging research related to sustainability, proved to be difficult and encountered much in-house opposition. The teaching staff argued that the idea of sustainability is much too vague, that it is not adequately substantiated by theory, and that it tends to be based on personal convictions and values rather than on empirical data and elaborated theories.

Another obstacle turned out to be the unwillingness of teaching staff to change their own module content and learning outcomes. One interpretation of this general resistance was found in the concept of educational organizations as expert organizations [8]. Lecturers can be considered as experts on whose knowledge and skills the organization is dependent: the more important their knowledge is for the organization, the more independently the experts can act [ibid.]. Their lack of willingness to engage in processes that do not recognize their expertise or try to undermine it is correspondingly limited. We concluded that it was therefore necessary to design the development process in such a way as not to trespass on their expert knowledge.

To promote transition of the curricula, the working group decided to set up a project that fostered sustainable development in existing courses in order to avoid further resistance from teaching staff. Starting from the premise that education for sustainable development requires reflection on personal values and ethical attitudes as well as a collaborative dialogue [9] that cannot simply be decreed from above, a method was chosen that started with the existing teaching conditions and credo of the staff. Instead of developing separate elective courses, this embedded solution was favoured because it was considered more likely to emphasise the fact that key competences in sustainable development are mandatory for graduates of the Bachelor's programme.

In summary, it can be said that the process of implementation was designed to be bottom-up rather than top-down. The expanded and "dynamized" model of sustainability outlined above was applied from the start to the courses in the study programme as a bottom-up data acquisition and development tool, as recommended by Wiesmann and Messerli [4]. The aim of this approach was that the concept of sustainability should be perceived as an open curriculum development project that would contribute to providing a stimulating environment for both research and teaching. The assessment tool provides access to the key dimensions, is suitable for a bottom-up strategy, and takes the relevant value systems of the stakeholders affected into account. The assessment tool and the implementation process also help ensure that existing contributions and content related to the topic of sustainability are more effectively harmonised, and that opportunities are provided for more in-depth study during courses. This inductive approach explains why action research processes [10] have served to guide the scientific progress which continues to be made. 


\section{Methods and Procedures}

The process of implementation was designed, carried out and reflected on as action research. Employees participating in the working group were also part of the research project. Initially all module supervisors were given relatively short training on assessment of the modules using the spider diagram (see Figure 1). The result of the process was regularly assessed by the working group and the next steps were determined on the basis of this assessment. This approach reflected the concept of "learning organization" [11], which includes developing in a desired direction through self-observation, field notes and qualitative interviews. Regular continuing education activities supported the process.

Figure 1. Spider diagram and its sustainability criteria (adapted from [12], based on a conception of sustainable development suggested by [4-7]).

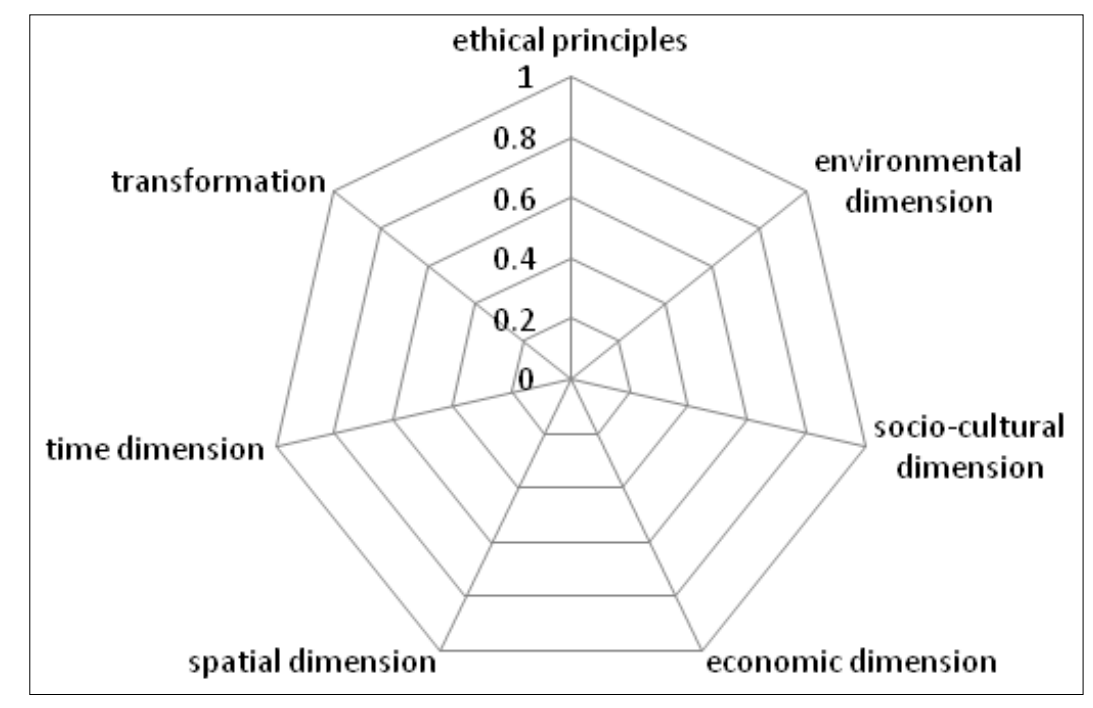

Assessment of sustainability content and completion of the spider diagram took place during educational workshops for lecturers. The task was to use a scale of 0 to 1 (in steps of 0.2 ) to assess how thoroughly the selected dimension was covered in the module in terms of both content and time. Teacher training was designed as a peer-to-peer teaching and learning situation. Participants received advice from the working group, whose expertise was only slightly greater than their own. However, the two-hour workshop was only the start of a longer-term fundamental process, co-designed by the lecturers themselves in an open-ended way. The process of optimising the programme took place iteratively: the persons responsible for teaching modules and courses implemented these processes independently, but were supported by formal guidelines. The same applied to students who were required to show how their Bachelor's thesis related to sustainable development (in a separate section).

To facilitate the integration of sustainability into the curriculum, the working group compiled the set of dimensions described above. Used as an assessment instrument, it reflects the relationship between course content and sustainable development. Its layout as a spider diagram (see Figure 1) is based on an assessment tool developed for describing ESD initiatives at primary schools (Swiss Foundation for Environmental Education [12]). The spider diagram enables an exploratory survey of the current situation to be carried out and can be used for self-assessment purposes. Although the 
assessment system lacks objective criteria and is based on individual assumptions, it increased the willingness of lecturers to cooperate.

\section{Results}

By means of a systematic pre-review of course contents and course specifications, the working group was able to demonstrate and confirm its hypothesis that the aspects of sustainable development already played a crucial but nevertheless mainly implicit role in numerous modules of the Bachelor's programme. When they became aware of this fact, resistance on the part of lecturers diminished for the first time. Secondly, it was found that there are modules which are closely connected to the topic and others that address aspects of sustainable development rather marginally. The following steps were therefore aimed at strengthening the coordination of content, at illustrating sustainable development as an integral and explicit part of the courses, and at supporting the faculty and the lecturers in developing their modules.

These workshops and teacher training sessions on applying the spider diagram helped to remove most resistance and win colleagues over to the working group's intentions. We assume the following reasons for the increased goodwill shown: firstly, it became clear that substantial changes were not necessary because many elements of sustainability already formed part of the courses; secondly, lecturers had a better understanding of what sustainability actually means and includes, and the purpose of its integration into courses.

Figure 2. Individual assessments of sustainability in four different modules: (a) Nature and Society, (b) Habitats in Switzerland, (c) Environmental Planning, (d) Environmental Education.

time dimension


Thirdly, participants reported that although the assignment of values was challenging (due to subjective interpretation regarding aspects of sustainability), the spider diagram was found to be a simple tool which is easy to apply and quickly provides an overview. All the workshop participants reported being motivated to fill in the diagram. We were also able to confirm our hypothesis that this spider diagram helps to increase awareness of implicit knowledge: participants reported their surprise when ascertaining that sustainable development already plays a crucial role in numerous modules of the Bachelor's programme. Therefore, after becoming familiar with the spider diagram, more and more lecturers started to look for and describe the explicit role of sustainable development in their module descriptions. Figure 2 shows examples of how sustainability is included in numerous modules.

As a result of the first two workshops and teacher training sessions, nearly a hundred module descriptions now contain a short section on sustainability. Figure 2 also displays the variety of individual assessments. These variations triggered a process among lecturers in which they reflected on further potential to include aspects of sustainability, and their commitment to developing module contents oriented towards sustainability has increased.

Relating the spider diagram to other sustainability assessment systems such as the «Global Reporting Initiative» (GRI) [13] or the Auditing Instrument for Sustainability in Higher Education (AISHE), the authors assume that a simple tool like the spider diagram has a far greater capacity to encourage lecturers to participate in the implementation process than a huge list of criteria, as used in the GRI. It can be considered as a simple «foot-in-the-door technique» [14]. The spider diagram was effective in fostering readiness to discuss sustainable development as part of courses and lectures. As a result, the willingness to address even ethical aspects of sustainable development increased among the natural scientists on our teaching staff.

As a spinoff, the Swiss Commission for UNESCO recognised the Bachelor's programme as an activity contributing to the «UN World Decade of Education for Sustainable Development in Switzerland» in spring 2010. This recognition was awarded for the first time ever to a Bachelor's degree programme in Switzerland, and has so far been accorded to no other programme.

The use of the spider diagram has been particularly valuable in maintaining the transition to sustainability and its further potential has already been recognised. In addition, the school management has encouraged the working group to continue the process of awareness-raising: on one hand, they provide support via personal coaching and training sessions to those lecturers of the faculty who want to address the issue in their classrooms and, on the other hand, consultation is provided for lecturers who are responsible for modules that deal only marginally with sustainability. The latter are encouraged to strengthen references to sustainable development in their courses and to treat the dimensions of sustainability in more depth.

The further implementation of sustainable development into more courses and modules which form part of the Bachelor's degree is the stated goal of the working group, in order to display responsibility towards people and the environment holistically in their curricula. It is their belief that sustainability should be represented as a key concern of the university management. Moreover, it should be sufficiently recognised as an important aspect of both teaching and research. Quality management as well as strategy building processes and the further education of lecturers and research associates will help the ZHAW Institute of Natural Resource Sciences to continue its sustainability transition, a process which is not as easy as it might seem. In this context, continuous use of the spider diagram is 
helping to coordinate and deepen implementation of sustainability issues in the curriculum. Based on our reflective research and meta-analysis of the ongoing process, a useful next step would be the introduction of periodic discussion forums. A first successful forum about ethical aspects of sustainable development included in the modules and the main study programmes already took place in January 2013. In January 2014 a discussion forum about transformation management is foreseen.

\section{Conclusions: Fostering Sustainable Development in the Curricula}

In the example shown, it was possible to anchor the implementation of sustainability more effectively in a Bachelor's degree programme through broadening the focus on sustainable development from the systemic to the normative level, as well as to the level of transformation. Some reservations expressed by lecturers about the concept (in discussions and with reference to the scientific literature) were addressed through a process that is characterized in the following.

The spider diagram focuses on the teaching content of lecturers and their concerns and priorities. It integrates and locates them in a very general theoretical framework, in which the issues are seen as important and stimulating in most content areas. Concrete analysis, starting from a concrete problem, is better suited to demonstrating the fruitfulness of the concept than a deductive approach. By applying the spider diagram to specific content, a reference to the system is created through a specific example. This avoids confusion and debate about systems and system boundaries, and also about approaches to their analysis. At the same time a concrete problem is transferred to the framework of sustainability analysis. From this point of view, the strengths of the model of sustainability are visible.

The inclusion of the normative dimension and the dimension of transformation has the potential to provide ideas for applied, practice-oriented curriculum design that go beyond specific disciplines and objects of research. The relationship to knowledge of change and transformation methods creates a common perspective on different teaching content, and thus forms a unifying link between various teaching contents throughout the curriculum. Lecturers and students are interested in these implementation and change perspectives, which most probably contribute to motivation for teaching and studying. The procedure chosen can be connected to this motivation. Besides the numerous and very varied teaching contents, a unifying concern is evident in the transformation perspective.

In the design of the process, principles were taken into account as required by the concept of sustainable development, the learning organization and lifelong learning. In this way an exciting framework was created, in which the lecturers were involved as experts. In this framework, the lecturers are not questioned in regard to their expert role, but are supported in it. The procedure has the potential to incorporate existing expertise into a comprehensive framework and thus enhance its value. The topic of sustainability is seen as an overarching theme in this context, to which the various disciplines and perspectives provide important contributions. The subject of sustainable development can thus be experienced from an objective viewpoint, and via the development of knowledge about ways to change systems. The dynamics of the concept within an organization become noticeable and effective. It can be postulated that the application of these principles within an organization and with lecturers also has an impact on the design of teaching.

Raising awareness of implicitly influential beliefs and values offers not only an interesting confrontation (with stakeholders' own beliefs), but also constitutes a step towards social debate on 
these issues. This level represents an interesting content component and facilitates a connection to social discussion of the development of sustainability.

The tool can be used to show the strengths of the contributions made in each module and also provides indications of where the strengths and weaknesses of a programme lie. It is thus a tool that not only helps lecturers to develop their own contributions to the curriculum further, but also enables the strands of the entire programme to be coordinated more effectively.

The authors believe that this very simple assessment tool proposed will be useful in conjunction with the participatory bottom-up process described to trigger positive developments for the integration of sustainability within an organization and curriculum of a university. Nevertheless, it is acknowledged that a course of study relating to environmental engineering may provide better and easier conditions for the implementation of sustainable development than other Bachelor's programmes.

\section{Acknowledgments}

The authors would like to thank Thomas Hofstetter, Reto Hagenbuch and Bettina Hendry, who as part of the working group assisted in developing the spider diagram. The authors are also grateful for the support of Margaret Lussi Bell and Nick Bell and for their help in proof-reading and translation. Finally, constructive comments of the anonymous reviewers are highly appreciated.

\section{Author Contributions}

Sandra Wilhelm Hamiti presented the spider diagram at the 3rd International Sustainability Conference, which was held 2012 in Basel. The team of university lecturers implemented the diagram in the Bachelor's programme in Natural Resource Sciences at the Zurich University of Applied Sciences by means of action research. This paper was written by Sandra Wilhelm Hamiti and Hans Wydler in a team work process.

\section{Conflicts of Interest}

The authors declare no conflict of interest.

\section{References and Notes}

1. Corcoran, P.B., Wals, A.E.J., Eds. Higher Education and the Challenge of Sustainability: Problematics, Promise and Practice; Kluwer Academic Press: Dordrecht, The Netherlands, 2004.

2. Network for Transdisciplinary Research. Sustainable Development at Universities Programme, 2013-2016; Call for Project Proposals; Td-net: Bern, Switzerland, 2012.

3. World Commission on Environment and Development. Our Common Future. Report of the World Commission on Environment and Development; Published as Annex to General Assembly document A/42/427; Development and International Co-operation: Environment, 2 August 1987.

4. Wiesmann, U.; Messerli, P. Wege aus den konzeptionellen Fallen der Nachhaltigkeit—Beiträge der Geographie. In Nachhaltige Entwicklung; Schweizerische Akademie der Geistes- und Sozialwissenschaften, Ed.; Schweizerische Akademie der Geistes- und Sozialwissenschaften: Bern, Switzerland, 2007; pp. 123-142. 
5. Wiek, A.; Binder, C. Solution spaces for decision-making-A sustainable assessment tool for city-regions. Environ. Impact Assess. Rev. 2005, 25, 589-608.

6. Thierstein, A.; Walser, M. Die nachhaltige Region. Ein Handlungsmodell; Schriftenreihe des Instituts für öffentliche Dienstleistungen und Tourismus. Beiträge zur Regionalwirtschaft; Haupt Verlag: Bern, Switzerland, 2000.

7. Thierstein, A.; Walser, M. Quality Management of Projects on Sustainable Development: An Evaluation Framework; Working Paper; Institut für Öffentliche Dienstleistungen und Tourismus, Universität St. Gallen: St. Gallen, Switzerland, 2005.

8. Laske, S.; Meister-Scheytt, C.; Küpers, W. Organisation und Führung; Waxmann: Münster, Germany, 2006.

9. Wals, A.E.J.; Corcoran, P.B. Sustainability as an Outcome of Transformative Learning. In Drivers and Barriers for Implementing Sustainable Development in Higher Education; Technical Paper No. 3; Holmberg, J., Samuelson, B.E., Eds.; UNESCO: Education for Sustainable Development in Action: Paris, France, 2006; pp. 103-108.

10. Elliot, J. Action Research for Educational Change; Open University Press: Buckingham, UK, 1991.

11. Senge, P.; Cambron-McCabe, N.; Lucas, T.; Smith, B.; Dutton, J.; Kleiner, A. Schools that Learn: A Fifth Discipline Fieldbook for Educators, Parents, and Everyone Who Cares about Education; Nicholas Brealey Publishing: London, UK, 2000.

12. Swiss Foundation for Environmental Education, Ed. Bildung für Nachhaltige Entwicklung-Handeln für die Zukunft; In Zusammenarbeit mit der Stiftung Bildung und Entwicklung und der Schweizerischen Unesco-Kommission: Bern, Switzerland, 2009. (In German)

13. Global Reporting Initiative (GRI). Sustainability Reporting Guidelines; Global Reporting Initiative: Amsterdam, The Netherlands, 2011.

14. Koger, S.; Winter, D. The Psychology of Environmental Problems, 3rd ed.; Taylor \& Francis Group: New York, NY, USA, 2010.

(C) 2014 by the authors; licensee MDPI, Basel, Switzerland. This article is an open access article distributed under the terms and conditions of the Creative Commons Attribution license (http://creativecommons.org/licenses/by/3.0/). 